\title{
Abdominal compartment syndrome - a rare complication of veno-venous extracorporeal membrane oxygenation for primary graft dysfunction following lung transplantation
}

\author{
L. Valeanu, M. Stefan, S. Andrei, P. Augustin \\ Centre Hospitalier Universitaire Bichat Claude Bernard, Paris, France
}

\begin{tabular}{|l|c|c|c|}
\hline & admission & before laparotomy & after laparotomy \\
\hline MAP (mmHg) & 70 & 50 & 75 \\
\hline NAD (ng/kg/min) & 150 & 750 & 400 \\
\hline SpO2 & 92 & 78 & 100 \\
\hline $\begin{array}{l}\text { ECMO rotation/ flow } \\
\text { (liters/minute) }\end{array}$ & & $2800 / 1$ & $3400 / 4$ \\
\hline $\begin{array}{l}\text { ECMO inflow pressure } \\
\text { (mmHg) }\end{array}$ & & -190 & -90 \\
\hline $\begin{array}{l}\text { ECMO outflow } \\
\text { pressure (mmHg) }\end{array}$ & & 200 & 120 \\
\hline $\begin{array}{l}\text { Intraabdominal } \\
\text { pressure (mmHg) }\end{array}$ & & 40 & 30 \\
\hline $\begin{array}{l}\text { Peak pressure } \\
\text { (cmH2O) }\end{array}$ & & 60 & 26 \\
\hline $\begin{array}{l}\text { Plateau pressure } \\
\text { (cmH2O) }\end{array}$ & $320 / 22 / 12$ & 47 & $240 / 10 / 16$ \\
\hline $\begin{array}{l}\text { Tidal volume (ml)/ } \\
\text { respiratory rate (per } \\
\text { minute)/ PEEP } \\
\text { (cmH2O) }\end{array}$ & & $240 / 24 / 12$ & \\
\hline
\end{tabular}

\section{Background:}

Primary graft dysfunction (PGD) is a severe form of ischemia reperfusion syndrome developing after lung transplantation (LT). Extracorporeal membrane oxygenation (ECMO) can be used in case of severe hemodynamic failure following PGD, but the massive fluid overload needed for adequate pump flow can lead to development of abdominal compartment syndrome (ACS) and the need for a decompressive laparotomy (1).

\section{Case report:}

A $46 \mathrm{~kg}, 54$ years old female was admitted to the ICU following bipulmonary lung transplantation for emphysema. The total ischemia time for the right lung was $7 \mathrm{~h} 56 \mathrm{~min}$, for the left lung 6 h $50 \mathrm{~min}$, with a 4 hours ex vivo lung perfusion.

There was no need for circulatory support using ECMO during the transplantation, but by the end of the surgery the patient received 8 liters of crystalloids and a continuous infusion of noradrehaline $(150 \mathrm{ng} / \mathrm{kg} / \mathrm{min})$ was initiated in order to restore an adequate hemodynamic status. The transesophageal echocardiography showed a normal biventricular function, and severe hypovolemia, with a "kissing" left ventricle and a superior vena cava collapse during inspiration.

After ICU admission, the patient developed a grade 3 PGD with persisting vasoplegic shock and was assisted with a venovenous femuro-jugular ECMO 2 hours later. After an initial successful hemodynamic resuscitation, impaired venous return and pump flow of less than $1 \mathrm{l} / \mathrm{min}$ were noted. Correct cannula position was confirmed using echocardiography. During the first 4 hours, 20 liters of crystalloids were administered and the noradrenaline dose increased to $750 \mathrm{ng} / \mathrm{kg} / \mathrm{min}$ under ECMO. Mesenteric ischemia, septic shock and anaphylactic shock were ruled out.
The ACS was diagnosed after measuring an intra-abdominal pressure of $40 \mathrm{mmHg}$ and a decompressive laparotomy was performed in the ICU, 4 hours after admission. Following decompression, the pump flow increased to $4 \mathrm{l} / \mathrm{min}$ and the noradrenaline dose decreased.

The multiple organ dysfunction progressively ameliorated, the ECMO was explanted 3 days later and the abdominal wall was closed 6 days later. The patient developed a ventilator associated pneumonia after the first week, but was finally extubated 14 days later and left the ICU after a total stay of 5 weeks, with no evidence of humoral or cellular graft rejection.

\section{Discussion:}

Primary graft dysfunction can develop rapidly after LT and the need for assistance using veno-venous ECMO is documented. The massive vasoplegic shock caused by the ischemiareperfusion syndrome can necessitate resuscitation with large doses of fluids and vasoconstrictors in order to obtain adequate ECMO pump flow, but in the same time the massive fluid overload can lead to formation of tense ascites and development of ACS, which will then worsen on its own the venous return and the pump flow.

\section{Learning points:}

Measurement of the intra-abdominal pressure should be considered in case of inappropriate venous return and pump flow, especially after massive fluid overload and decompressive laparotomy should be realized as soon as possible.

\section{References:}

(1) Augustin P. et al. Abdominal compartment syndrome due to extracorporeal membrane oxygenation in adults. Ann Thorac Surg 2010; 90: e40-41. 